\begin{tabular}{|l|l|}
\hline $\begin{array}{l}\text { Las artes visuales latinoamericanas y caribeñas: su difusión en Cuba a través de una } \\
\text { muestra de las principales publicaciones seriadas (en soporte papel) en el período } \\
\text { comprendido entre } 1990 \text { y } 2011\end{array}$ & Titulo \\
\hline López Hernández, Julienne - Autor/a; & Autor(es) \\
\hline $\begin{array}{l}\text { De Raíz Diversa. Revista Especializada en Estudios Latinoamericanos (Vol. 2 no. 4 } \\
\text { jul-dic 2015) }\end{array}$ & En: \\
\hline México D.F. & Lugar \\
\hline $\begin{array}{l}\text { Programa de Posgrado en Estudios Latinoamericanos, Universidad Nacional } \\
\text { Autónoma de México }\end{array}$ & Editorial/Editor \\
\hline 2015 & Fecha \\
\hline $\begin{array}{l}\text { Publicaciones; Artes visuales; Arte; América Latina; Cuba; } \\
\text { Artículo }\end{array}$ & Colección \\
\hline $\begin{array}{l}\text { "http://biblioteca.clacso.edu.ar/Mexico/ppel-unam/20160627034303/Julienne_Lopez_Las_artes_visuales_latinoamericanas_y_caribenas- } \\
\text { su_difusion_en_Cuba_a_traves_de_una_muestra_de_las_principales_publicaciones_seriadas_en_soporte_papel_en_el_periodo_compr } \\
\text { endido_entre_1990_y_2011.pdf" }\end{array}$ & Temas \\
\hline $\begin{array}{l}\text { Reconocimiento-No Comercial-Sin Derivadas CC BY-NC-ND } \\
\text { http://creativecommons.org/licenses/by-nc-nd/2.0/deed.es }\end{array}$ & Tipo de documento \\
\hline
\end{tabular}
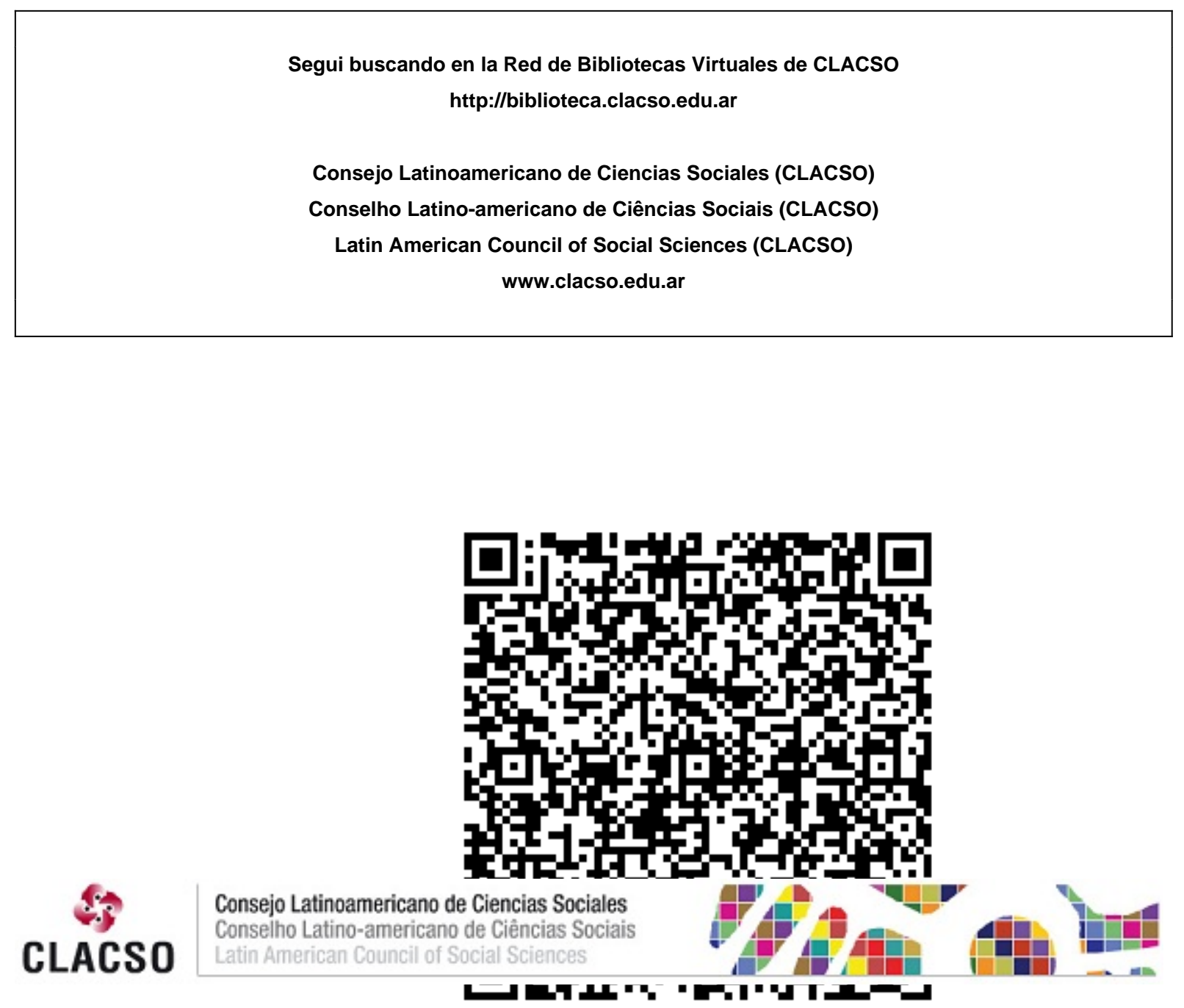


\title{
Las artes visuales latinoamericanas y caribeñas: su difusión en Cuba a través de una muestra de las principales publicaciones seriadas (en soporte papel) en el período comprendido entre 1990 y 2011
}

\author{
JULIENNE LÓPEZ HERNÁNDEZ*
}

RESUMEN: El presente trabajo tiene por tema: La difusión de las artes visuales latinoamericanas y caribeñas en Cuba, a través de una muestra de las principales publicaciones seriadas (en soporte papel) en el período comprendido entre 1990 y 2011, a saber: Artecubano, Arte por Excelencias, Arte Sur, Casa de las Américas y Anales del Caribe. Está dirigido a reconocer qué tipo de conocimiento sobre las artes visuales de América Latina y el Caribe se difunde en las principales publicaciones cubanas; quiénes han sido las principales voces críticas que han intervenido en esta acción difusora; y cuánto han aportado estas a la comprensión de un fenómeno tan amplio, diverso y, a la vez, esencial para los estudiosos del arte de nuestra región. Para ello se caracterizan y valoran los canales de difusión, la naturaleza de la información que se difunde y las voces críticas que intervienen; para arribar a la conclusión de que la difusión de las artes visuales latinoamericanas y caribeñas, a través de dichas publicaciones cubanas durante los años 1990-2011, se enriquece con respecto a etapas precedentes y refleja un alto nivel de actualidad y pluralidad de temas y miradas en torno al quehacer artístico contemporáneo de nuestra región.

Palabras Clave: artes visuales latinoamericanas, publicaciones cubanas.

Abstract: The main topic of this article is the diffusion of Latin American and Caribbean visual arts in Cuba through a sample of major serial publications in the period between 1990 and 2011, namely: Artecubano, Arte por Excelencias, Arte Sur, Casa de las Américas and Anales del Caribe. The author's aim is to assess what type of information about visual arts in Latin America and the Caribbean is spread by the major Cuban publications; to identify the main critics who have contributed to this diffusion and to the understanding of such a large and diverse phenomenon which is at the same time essential for the art specialists of the region. The diffusing channels, the nature of the information and the critical voices involved have been carefully characterized and evaluated. The author concludes that the diffusion of Latin American and Caribbean visual arts through

Profesora del Departamento de Estudios Teóricos y Sociales de la Cultura, de la Facultad de Artes y Letras de la Universidad de La Habana, Cuba. < julienne@fayl.uh.cu y juliennelh@gmail.com> 
the analyzed Cuban publications during the years 1990-2011 has been enriched in comparison with the previous periods, it keeps up with the current affairs, and reflects a high level plurality of themes and approaches to the contemporary art scene of the region.

KEYWORDS: Latin American visual arts, Cuban publications.

RECIBIDo: 10 de diciembre de 2014 Aceptado 16 de abril 2015.

\section{$\mathrm{P}$} ara la comunidad académica cubana, y en especial para los estudiosos de las artes visuales, resulta de inestimable interés la posibilidad de examinar cómo se ha conocido y valorado en nuestro país la producción artística de la región latinoamericana y caribeña en términos de difusión. Importantes eventos internacionales como las sucesivas ediciones de la Bienal de La Habana, y otros acontecimientos exhibitivos relevantes como los que auspicia de manera sistemática la Casa de las Américas -en cuanto a grabado y fotografía, por ejemplo- nos ponen en contacto directo con segmentos muy actualizados de esa producción y del pensamiento teórico que se mueve en torno a la misma.

Asimismo, numerosas exposiciones individuales y colectivas que tienen lugar en diferentes espacios galerísticos del país, con relativa frecuencia dan a conocer la obra de no pocos creadores del área, consagrados y noveles. Muy especialmente, las sucesivas ediciones de la Bienal de La Habana han dado fe de la efervescencia artística regional durante las últimas décadas, sobre todo a partir del boom que vivió esa producción durante el último decenio del siglo pasado.

Aún así, se tiene la impresión de que la difusión de esas muestras ha sido escasa y que, en general, es limitada la información que circula en el ámbito cubano sobre el arte de la región a la que pertenecemos. Tal percepción no puede juzgarse al margen de las dificultades que entraña para los estudiosos cubanos el acceso a Internet y la reducida existencia en nuestras bibliotecas de un stock de revistas y catálogos de producción internacional que pudieran cubrir el vacío informativo que padecemos. Falta aquilatar, sin embargo, en qué medida las propias publicaciones cubanas le han dado cobertura al acontecer de las artes visuales contemporáneas de Latinoamérica y el Caribe. A tales efectos resulta prudente reconocer qué tipo de conocimiento sobre las artes visuales de América Latina y el Caribe se difunde en las principales publicaciones cubanas; quiénes han sido las 
primordiales voces críticas que han intervenido en esta acción difusora; y cuánto han aportado éstas a la comprensión de un fenómeno tan amplio, diverso y, a la vez, esencial para los estudiosos del arte en nuestro país.

Es menester precisar que para referirse a América Latina y el Caribe se acoge la noción martiana de Nuestra América que contempla a los territorios continentales (desde el Río Bravo hasta la Patagonia) y que también abraza al Caribe todo, incluyendo los territorios (insulares y continentales) anglófonos y francófonos. Sin embargo, es perfectamente explicable que este estudio sobre la difusión de las artes visuales latinoamericanas y caribeñas en las publicaciones cubanas no considera el compendio de aquellos trabajos dedicados exclusivamente a la producción artística nacional. ${ }^{1}$

Asimismo, debe señalarse que en el orden temático el objeto de estudio se centra en la información referida a las artes visuales; tanto a la producción artística como al pensamiento teórico en torno a la misma. Se excluyen los estudios expresamente dedicados a la arquitectura y al urbanismo, toda vez que estos se hallan preferentemente concentrados en otros soportes especializados cuya revisión presupone otras pautas de localización y análisis. También compete aclarar que en lo que respecta a la producción artística audiovisual solo se asumen aquellas expresiones contempladas dentro de los canales de circulación de las artes plásticas, las que resultan genéricamente abrazadas bajo la nominación de video arte o videocreación. En cuanto a la selección de una muestra que contemple a las principales publicaciones seriadas cubanas en soporte papel' correspondientes al período 1990-2011, se determinó trabajar con las tres revistas especializadas en artes visuales -Artecubano, Arte por Excelencias $y$ Arte Sur- e incluir, asimismo, otras dos publicaciones de perfil cultural no especializado en artes visuales -Casa de las Américas y Anales del Cari$b e$ - las que constituyen órganos de una institución cultural, la Casa de las Américas, de excepcional protagonismo en el estudio, la investigación y la promoción de la cultura artística de nuestra región.

\footnotetext{
${ }^{1}$ Como quiera que en las publicaciones nacionales la presencia de las artes visuales cubanas es cuantitativamente mayoritaria, su revisión supondría un estudio aparte que no contamine la valoración sobre la difusión del arte regional. De este modo, solo se asumen los trabajos que incluyen al arte cubano cuando este es abordado como parte integrante del fenómeno regional.

2 No fueron incluidas las publicaciones especializadas en soporte digital Arteamérica, y el boletín digital de Arte por Excelencias, puesto que, por su propia naturaleza, presuponen canales de circulación y de accesibilidad totalmente diferentes, que las apartan de los propósitos de esta investigación.
} 
Para la presente investigación se partió del método histórico-lógico para vertebrar la estructura interna del trabajo en los términos del arco temporal que se decidió analizar. En paralelo, se aplicó el método analítico-sintético para intervenir el estudio de los textos y arribar a una valoración integral. Por otro lado, las técnicas de investigación aplicadas fueron la revisión y análisis de los textos y el fichaje bibliográfico de cada uno de ellos. También se incluyó la entrevista a expertos cubanos en la materia, con el propósito de identificar el conjunto de las publicaciones que integran la muestra objeto de estudio y confrontar aspectos relacionados con la caracterización de las mismas.

Respecto a la revista Artecubano -órgano del Consejo Nacional de las Artes Plásticas- vale señalar que, tras haber emergido precisamente en medio de la efervescencia del movimiento plástico nacional hacia mediados de los noventa, se ha convertido en uno de los canales fundamentales no solo para la difusión del acontecer artístico nacional, sino también para la promoción de las artes visuales de América Latina y el Caribe en los últimos años. Destaca, en particular, el espacio concedido en sus páginas a las diferentes ediciones de la Bienal de La Habana y a la presencia que en este evento ha tenido el arte regional. Por su parte, Arte por Excelencias y Arte Sur emergieron en el contexto editorial cubano en el año 2009 y sobresalen, desde entonces, por otorgar un protagonismo hasta ese momento inédito a las artes visuales latinoamericanas y caribeñas, con un complemento visual y un nivel de actualidad realmente loables. Específicamente Arte por Excelencias constituye un soporte de capital importancia para el estudio planteado, dado el nivel de especialización y de actualidad con que aborda el acontecer artístico internacional con singular interés hacia nuestro contexto geográfico. Por su parte, la joven revista Arte Sur ha devenido una publicación promisoria en lo que atañe a la divulgación del pensamiento sobre el arte y sus principales problemáticas en esta parte del mundo. En cuanto a Casa de las Américas y Anales del Caribe resulta innegable, como ya se ha señalado, el papel desempeñado por ambas publicaciones en favor de la investigación y el conocimiento de la cultura artística latinoamericana y caribeña, a tono con la ingente labor que desarrolla la institución que las auspicia.

Por tanto, el análisis de la difusión de las artes visuales latinoamericanas y caribeñas en las publicaciones seriadas cubanas (1990-2011) se centra en la valoración cuantitativa y cualitativa -por separado en cada una de las publicaciones- de la información difundida y de las voces críti- 
cas que en ello intervienen. Se analizan además los niveles de difusión de las artes visuales latinoamericanas y caribeñas en las páginas de cada una de dichas publicaciones, teniendo en cuenta la naturaleza de los textos que en ellas se presentan, las temáticas abordadas y los colaboradores; y se concluye con el necesario balance general de la información acopiada en el conjunto de las cinco publicaciones.

\section{LA DIFUSIÓN DE LAS ARTES VISUALES LATINOAMERICANAS Y CARIBEÑAS EN LAS PUBLICACIONES SERIADAS CUBANAS (1990-2011): ARTECUBANO, ARTE POR EXCELENCIAS, ARTE SUR, CASA DE LAS AMÉRICAS Y ANALES DEL CARIBE}

Revista Artecubano

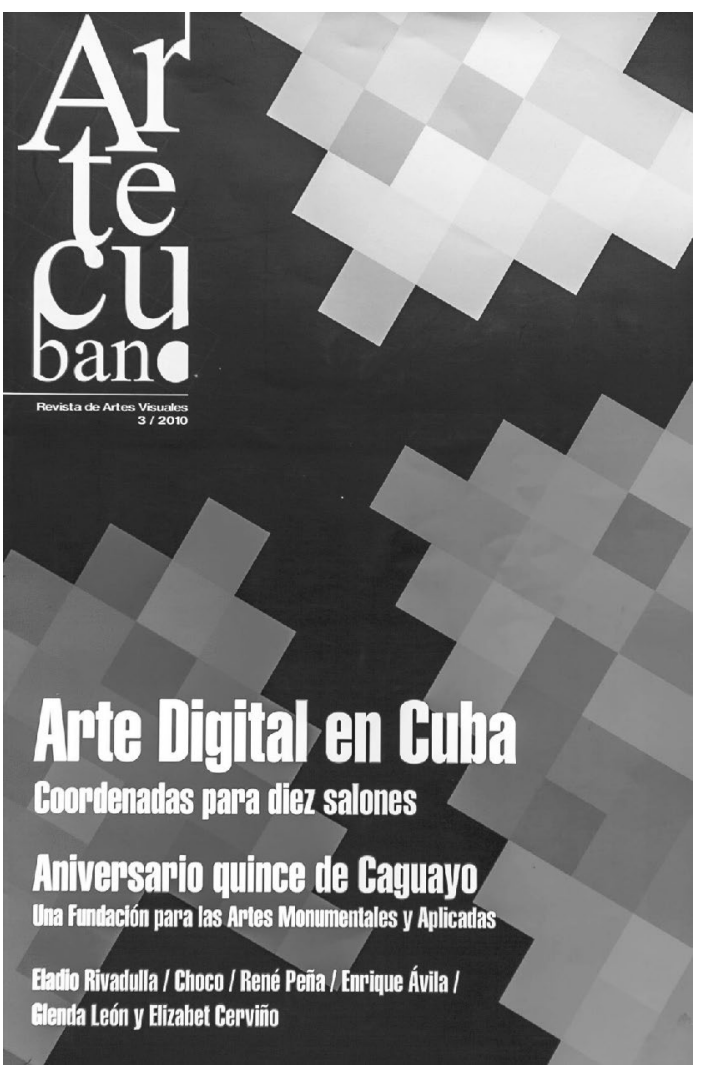

El espectro temporal revisado en la revista Artecubano cubre el período 1995-2011 y comporta una cifra de treinta y seis números de los cuales dieciséis han dado cabida a la temática en estudio. La mayoría de los trabajos localizados se han desplegado como artículos de fondo (autónomos) en las páginas de la publicación, o bajo la sección "Ruta Crítica", aunque también han figurado de manera puntual en prácticamente todas de las secciones, tales como "Dossier", "Lecturas", "Exposiciones", "Pensando alto", "Hablando por sí mismo", "Otros espacios" y "Entrevista". Se han identificado un total de treinta y cinco trabajos, los

cuales constituyen mayoritariamente reseñas, textos ensayísticos y, en menor medida, entrevistas y reseñas de libros. No se localizó ningún estudio monográfico de artista latinoamericano o caribeño no cubano. 
La dominante presencia de las reseñas (las que suman dieciocho) refleja la primacía de artículos de una extensión relativamente breve (de dos a cuatro páginas máximo), pero portadores del indiscutible mérito de haber tributado a la memoria crítica de importantes exposiciones personales de reconocidos artistas del área que han exhibido en Cuba, como la de la mexicana Lucía Maya, en la Casa de las Américas; la del puertorriqueño Antonio Martorell en la Facultad de Artes y Letras de la Universidad de La Habana, entre otras. En cuanto a las exposiciones colectivas exhibidas en Cuba en las que han figurado artistas cubanos, caribeños y latinoamericanos destacan: "El maíz es nuestra vida" y "Género, (trans) género y los (des)generados" -ambas celebradas en el marco de la x Bienal de La Habana-, así como "Iberoamérica Pinta", la cual agrupó en la Casa de las Américas a un amplio colectivo de creadores latinoamericanos, incluyendo varios cubanos. Asimismo se dio cobertura a una interesante muestra colectiva de grabado chileno que bajo el título "El arte en el Cobre" tuvo lugar en el Centro de Arte Contemporáneo Wifredo Lam. Un temprano texto de interés es la reseña dedicada a comentar la renombrada muestra "Cocido y Crudo", presentada en España en el año 1996, en la que se pone de relieve la oportuna inserción del arte latinoamericano en el circuito europeo.

Un lugar de importancia nada desdeñable entre las reseñas lo ha ocupado el recuento valorativo de algunos eventos, premios, simposios y bienales, que demuestran el creciente auge de certámenes artísticos en nuestra área geográfica. Entre los que han tenido lugar en Cuba aglutinando a creadores de toda la región se hallan: la sexta edición del Premio Ensayo Fotográfico que convoca la Casa de las Américas; la quinta edición del Premio La Joven Estampa (auspiciado por la misma institución) y el vi Simposio Internacional de Cerámica Artística en Puerto Príncipe (Camagüey). Entre los eventos internacionales celebrados fuera de Cuba se ubica la reseña dedicada a los Salones Regionales de Artistas de Colombia. En cuanto a reseñas de libros solo se localizaron dos: Visión del Arte Latinoamericano de la década de 1980, volumen de un colectivo de autores latinoamericanos coordinado por el Centro de Arte Contemporáneo Wifredo Lam (con financiamiento de la UnEsco) y el libro Huellas Críticas, del peruano Juan Acha.

Llama poderosamente la atención el conjunto de catorce textos ensayísticos que aluden con un enfoque más abarcador al arte regional; como sucede con el estudio sobre el arte contemporáneo en la cuenca caribeña y con el trabajo dedicado al análisis de la producción audiovisual en el 
área; así como con los que se acercan a la labor de creadores latinoamericanos y caribeños, en fructífero diálogo con artistas cubanos. Tal es el caso del estudio centrado en el quehacer de las fotógrafas Martha María Pérez (Cuba) y Eugenia Vargas (Chile).

Por supuesto, este tipo de interconexiones asoma también en varios de los textos ensayísticos que discursan sobre las sucesivas ediciones de la Bienal de La Habana. Es perfectamente explicable el tratamiento especial de que ha sido objeto este evento en las páginas de Artecubano, toda vez que la revista es órgano formal del Consejo Nacional de las Artes Plásticas de Cuba. Especial interés a los efectos de este estudio revisten entre otros: el texto dedicado a evaluar específicamente la participación latinoamericana en la octava edición del certamen; el análisis crítico de la fotografía en la novena edición; y en sentido general, los trabajos más abarcadores que sobre el evento se han publicado a propósito de sus celebraciones durante la segunda mitad de los noventa y la primera década de este siglo.

Las entrevistas contenidas en Artecubano, aunque en verdad muy pocas (solo tres), representan una útil contribución dado que dan a conocer la obra y el pensamiento crítico de figuras de indiscutible relieve, a saber: el artista puertorriqueño Víctor Vázquez, el creador mexicano Guillermo Gómez Peña, y el culturólogo y crítico paraguayo Ticio Escobar.

En sentido general, la presencia del arte de Latinoamérica y el Caribe en las páginas de la revista Artecubano es bastante desigual en términos de frecuencia. Se han localizado números donde aparecen desde dos hasta cuatro trabajos -incluso, se da un caso de seis textos, aunque estos se relacionan con la Bienal de La Habana-, mientras que en más de la mitad de los volúmenes no figura ningún artículo sobre el tema analizado. Revisados en el arco temporal de la publicación, se verifica que durante su primer quinquenio acumuló dieciocho trabajos, mientras que en los últimos once años solo alcanzó a contemplar diecisiete. En este sentido, es comprensible que la revista intentara centrar cada vez más su atención en el acontecer artístico nacional, pero resulta un hecho constatable que relegó un tanto su compromiso con el arte latinoamericano y caribeño, aún mucho antes de la aparición de las dos nuevas publicaciones especializadas que se insertaron en el panorama editorial cubano a la altura del año 2009.

No obstante, habría que reconocer que, cuando Artecubano optó por abordar el arte de América Latina y el Caribe, lo hizo convocando firmas de indiscutible autoridad en dicha materia, escogiendo a sus colaboradores entre ese reducido conjunto de investigadores, curadores y docentes 
cubanos que han fraguado una sólida trayectoria en este campo del saber. Así, las páginas de la revista han incorporado textos de: Yolanda Wood, Profesora Titular de Arte Caribeño de la Universidad de La Habana y Directora del Centro de Estudios del Caribe de la Casa de las Américas; Ibis Hernández Abascal, Margarita Sánchez y José Manuel Noceda, especialistas los tres del Centro de Arte Contemporáneo Wifredo Lam, quienes atienden el área de Latinoamérica y el Caribe; Llilian Llanes, por largo tiempo Directora del referido Centro Lam y Directora de la Bienal de La Habana; Lesbia Vent Dumois, artista y curadora que fungió durante muchos años como Directora de Artes Plásticas de la Casa de las Américas y que luego se desempeñó como Vicepresidenta de esa institución; junto a otros reconocidos críticos como Antonio Eligio Fernández (Tonel), Eugenio Valdés, Virginia Alberdi y Pedro de la Hoz. Mientras que, entre los colaboradores internacionales figuran el crítico de arte alemán Wolfgang Becker, la especialista brasileña en artes visuales Marissa Flórido, y el poeta, crítico y curador español Adolfo Montejo. Suman un total de veintiséis (en su mayoría cubanos) las voces críticas que durante más de tres lustros han contribuido a la difusión y mejor comprensión del quehacer artístico de nuestra región, a través de esta publicación pionera como soporte especializado en artes visuales.

\section{REVISTA ARTE POR EXCELENCIAS}

Por su parte, Arte por Excelencias ha recibido la más calurosa acogida por los estudiosos del arte en Cuba y ha demostrado un eficaz poder de convocatoria ante las más prestigiosas voces críticas que se interesan por la producción artística de América Latina y el Caribe. Así lo evidencian los cuarenta y ocho trabajos que, a lo largo de sus primeros tres años y once ediciones, han centrado la atención en diferentes aristas de este universo temático.

Las páginas de esta publicación acogieron un total de veintidós reseñas de importantes eventos culturales sucedidos a lo largo del último trienio en nuestro continente, abordando certámenes que abarcan desde importantes bienales, hasta algunas de las más relevantes muestras colectivas. En este sentido se destaca y agradece la inmediatez con que la revista ha reseñado eventos que marcan el auge promocional y exhibitivo del arte de América Latina y el Caribe, como son: la x Bienal de Cuenca, la Ix Bienal de Video y Artes Mediales en Chile, la I Trienal de Chile, la Trienal Poli- 
gráfica de San Juan, la II Bienal de Tipografía en Buenos Aires, la Bienal de Arte de Panamá y la Bienal de Curitiba, en Brasil.

Este amplio espectro se enriquece con la inclusión de reseñas dedicadas a exposiciones colectivas e individuales entre las que figuran: "Paraguay Esquivo"; "Rastros, el ojo privado"; la exposición realizada en Casa de las Américas por Julio Le Parc en el año 2009; "Cartografías disidentes"; "Campo Expandido"; "Cinética”; “Desacuerdos”; y "Paraguay rapé”, entre otras.

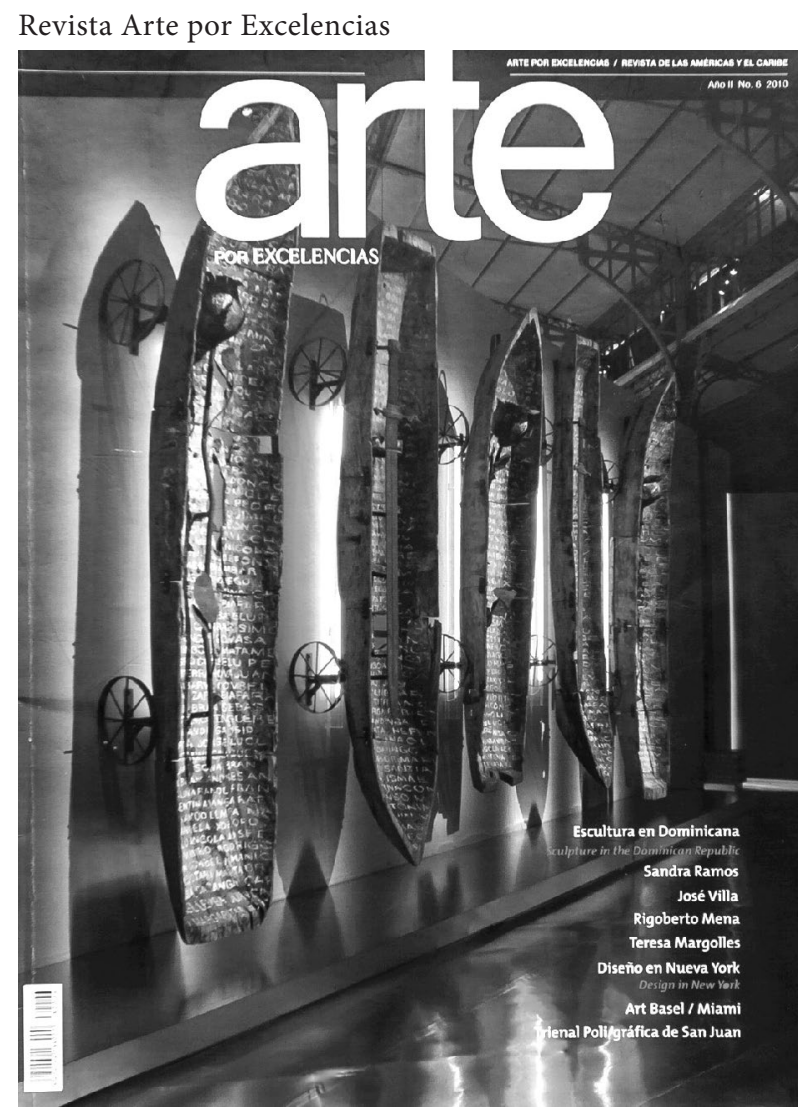

También cobran un peso importante en Arte por Excelencias los textos monográficos que se ocupan del comentario crítico y, en ocasiones, del análisis en profundidad de las poéticas individuales de artistas de gran prestigio internacional, junto a otros menos reconocidos o apenas emergentes en la escena plástica regional. Este tipo de texto -suman nueve en 
total- ${ }^{3}$ amplía el diapasón de conocimientos acerca de la producción plástica que se gesta ahora mismo en nuestra región, a la vez que aporta una útil información visual que mucho agradece el lector cubano, dadas las limitadas posibilidades de acceso a Internet que priman entre nosotros. Entre las figuras se encuentran: la colombiana Libia Posada, la boliviana Alejandra Alarcón, la mexicana Teresa Margolles, la anglo-argentina Sara Hooper, la argentina Dolores Cáceres, el uruguayo Luis Camnitzer, el brasileño José Damasceno y el chileno Edwin Rojas. Esta relación nominal pone de relieve el ancho espectro geográfico que cubren las voces críticas que colaboran con la publicación, destacando el hecho de que no solo se atienden figuras pertenecientes a países tradicionalmente privilegiados por la crítica especializada -como México, Brasil y Argentina- sino también a otros menos favorecidos como Colombia, Chile, Uruguay y Bolivia. Igualmente llama la atención la mayoritaria presencia de artistas mujeres las que, sin duda, están desempeñando un papel muy activo en la plástica regional.

Con menor presencia numérica -cinco trabajos en total- pero significativo interés para los estudiosos del arte latinoamericano y caribeño, la publicación ha otorgado espacio a las entrevistas. Estas han constituido eficaces vehículos para indagar en la trayectoria y el quehacer actual de destacadas figuras, con el particular atractivo de conferirle voz propia a los creadores, quienes ahondan no solo en su trabajo personal, sino también en disímiles problemáticas del arte contemporáneo. Otro tanto ocurre cuando los entrevistados son prestigiosos investigadores, críticos y curadores. En tal sentido resaltan los trabajos de este corte que han permitido socializar los testimonios y opiniones de personalidades como el curador cubano José Manuel Noceda, el renombrado artista brasileño Cildo Meireles, el destacado creador puertorriqueño Antonio Martorell, el artista chileno Iván Navarro y la artista mexicana Ambra Polidori.

Por razones comprensibles, los textos ensayísticos constituyen uno de los segmentos más enjundiosos, los cuales le ofrecen al lector de la revista Arte por Excelencias en las once ediciones que quedan comprendidas en el periodo analizado, doce trabajos de este tipo. Ellos se caracterizan por el nivel de actualidad y profundidad, así como por el rigor teórico, denotando interesantes entrecruzamientos entre los saberes de la historia del

3 Esta cifra no incluye las breves fichas curriculares alusivas a los creadores promocionados en la sección fija "La Caricatura", a través de la cual se ha dado a conocer la labor de dibujantes humorísticos de países como Perú, México, Brasil, Cuba, Colombia, Chile y Argentina. 
arte, la filosofía, la psicología, la antropología cultural y otras disciplinas. En ellos se abordan eventos de gran interés para los creadores, curadores, críticos e investigadores de arte latinoamericano; se problematiza sobre cuestiones particulares del arte de determinados países de nuestro continente y, en sentido general, se potencia la reflexión al interior mismo del arte latinoamericano y caribeño.

Algunos temas de singular importancia abordados, ya sea por lo poco explorados que han sido hasta hoy, o por su contribución a un conocimiento más abarcador de los procesos artísticos en Latinoamérica y el Caribe han sido, entre otros, los dedicados a: el análisis del arte caribeño del último decenio del siglo xx; la evaluación de la inserción del área centroamericana en el ámbito artístico regional e internacional; el comportamiento del denominado Arte Público en Sur América; y las miradas crítico valorativas concentradas en contextos nacionales, como las dedicadas a: el arte abstracto en Argentina, el escenario escultórico en la República Dominicana, el panorama actual de las artes visuales en Nicaragua, el diseño en Brasil, y el proyecto artístico Entijuanarte Revoluciona (desarrollado en México).

Es un hecho que Arte por Excelencias de esta forma da respuesta a una necesidad que, hasta hace muy poco tiempo, las publicaciones seriadas cubanas solo podían atender de manera puntual y asistemática, incluso en el caso de Artecubano (la única de carácter especializado en artes visuales) que lógicamente privilegia, como ya se ha señalado, la difusión del acontecer artístico nacional. Con Arte por Excelencias, cuyas páginas han acogido un total de cuarenta y ocho trabajos vinculados a la temática en estudio, se está en presencia de un soporte altamente plural e inclusivo que acoge las más variadas tendencias y manifestaciones del arte contemporáneo. Al focalizar el acontecer artístico reciente en los países de nuestra área geográfica, esta revista le confiere una dimensión de mayor alcance -cuantitativo y cualitativo- a los niveles de difusión en Cuba de las artes visuales de América Latina y el Caribe, contribuyendo con creces al conocimiento y estímulo de la investigación histórico-artística sobre este campo temático.

Tales méritos descansan, en buena medida, en la multiplicidad y el prestigio de las firmas que han colaborado con la revista en estos once números. Un total de treinta y nueve autores han publicado aquí sus textos, distinguiéndose entre los de más frecuente aparición: los cubanos Rufo Caballero, Nahela Hechavarría y José Veigas (a cargo de secciones fijas), Norberto Codina (Cuba), Ibis Hernández (Cuba), Carolina Lara (Chile) y 
Adriana Almada (Paraguay). Destacados estudiosos y críticos nacionales como Yolanda Wood, Nelson Herrera Ysla, David Mateo, Antonio Eligio Fernández (Tonel), Elvia Rosa Castro, y otros no cubanos como Vanessa Droz (Puerto Rico), Cecilia Ochoa (México) y Guillermo Vanegas (Colombia) han prestigiado una publicación en la que puede verificarse una modesta contribución al desentrañamiento de procesos del arte contemporáneo en las Américas y el Caribe.

\section{REVISTA ARTE SUR}

Por otro lado, la revista Arte Sur es la más joven de las publicaciones comprendidas en este análisis. Sin embargo, dado su perfil temático, con

Revista Arte Sur

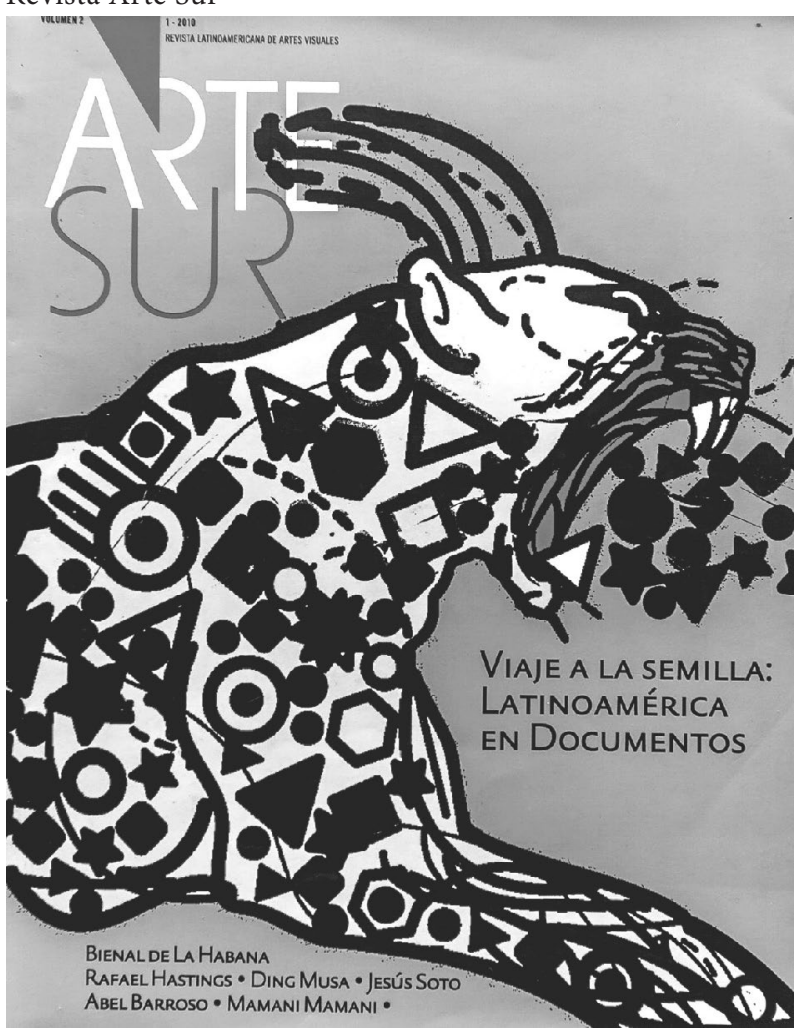

apenas dos entregas se colocó en posición de liderazgo en la difusión de las artes visuales de nuestra región. En sus páginas se han presentado cuarenta $y$ dos trabajos que contemplan un enjundioso caudal de textos ensayísticos, estudios monográficos de artistas, entrevistas y reseñas de máxima actualidad.

Sobresalen en calidad y cantidad (sumando un total de veintiún) los textos ensayísticos que en los dos números que forman parte del periodo analizado han engrosado las páginas de la revista. Los mismos ponen de relieve el interés no solo por la producción artística en sí, sino por el análisis crítico de otros 
aspectos relacionados con los circuitos exhibitivos y, en específico, con el tema del mercado y la consabida atención a canales tan diversos de circulación y comercio del arte como las bienales, las ferias internacionales, el coleccionismo, las subastas, etc.

Particularmente valiosos resultan los estudios que iluminan los procesos de desarrollo del arte en países poco tratados en la historiografía del arte regional como es el caso de Ecuador -a través de un estudio del tema del paisaje en esa nación-y de Martinica. También son justipreciadas manifestaciones en específico, como el diseño y la videocreación, esta última analizada en un texto expresamente dedicado al videoarte brasileño. No menos importantes resultan las utilísimas aproximaciones a asuntos problémicos de indudable vigencia, como la cuestión identitaria en el campo artístico y los aportes del arte latinoamericano y caribeño al resto del mundo, junto a determinados análisis regionales centrados en aristas temáticas muy sugerentes, como la del tratamiento del cuerpo en el arte caribeño contemporáneo.

Son varias las exposiciones y eventos reseñados a lo largo de estos dos números. A través de once textos de este tipo se tiene acceso al nivel de inserción en los circuitos artísticos internacionales que en los últimos años han conseguido muchos de nuestros creadores. Sobresalen en el primer número de la revista las reseñas de la vir Bienal del Mercosur, la xxviII Bienal de Sao Paulo, la Xvi Bienal de Arte Paiz (Guatemala), la Bienal Arte Nuevo Interactiva (México), la vi Bienal de Artes Visuales del Istmo Centroamericano, y la exposición itinerante "Herejías", del fotógrafo mexicano Pedro Meyer. Mientras que la segunda entrega alberga un enjundioso conjunto de trabajos sobre la décima edición de la Bienal de La Habana, ponderando, en especial, la participación de los creadores latinoamericanos y caribeños en este importante evento internacional.

Por lo demás, es de justa mención el lugar que ocupa la modalidad de la entrevista en las páginas de Arte Sur, con un total de cinco textos. Estos incluyen la entrevista que en el primer número se realiza a los curadores latinoamericanos Alberto Grotessi, Jorge Sepúlveda y Raúl Moarquech, acerca del tema macro del arte en la región (agrupadas en un texto único), y las que en la segunda entrega dieron cabida a las voces de un conjunto de cuatro artistas: el peruano Rafael Hastings, el boliviano Roberto Mamani, el mexicano Guillermo Gómez Peña y el brasileño Paulo Bruscky, quienes en sus respuestas rebasan el ámbito de sus poéticas personales para aportar lúcidos 
criterios sobre problemáticas del arte contemporáneo. Tampoco faltan los trabajos monográficos -cinco- dedicados a figuras como la artista guatemalteca Regina Galindo, la argentina Mónica Girón, el fotógrafo brasileño Ding Musa y los creadores venezolanos Bárbaro Rivas y Jesús Rafael Soto.

Un total de treinta y ocho colaboradores han intervenido en los dos números de Arte Sur, conformando de manera temprana un concierto de voces que enriquece esa provechosa pluralidad de miradas. Destacan entre ellos nuestros más prestigiosos académicos, investigadores y curadores especializados en el área temática que nos ocupa - Adelaida de Juan, Yolanda Wood, José Manuel Noceda, Ibis Hernández, Margarita Sánchez, Nelson Herrera Ysla, Nahela Hechavarría y Lesbia Vent Dumois- juntos a los brasileños Marissa Flórido, Leonor Amarante y Moacir Dos Anjos, la venezolana Isabel Huizi y el español Adolfo Montejo.

\section{REVISTA CASA DE LAS AMÉRICAS}

El arco temporal analizado en la revista Casa de las Américas (1990-2011) se concreta en la revisión de ochenta y ocho números. De ellos se localizaron textos sobre las artes visuales de nuestra región en diecisiete números,

Revista Casa de las Américas

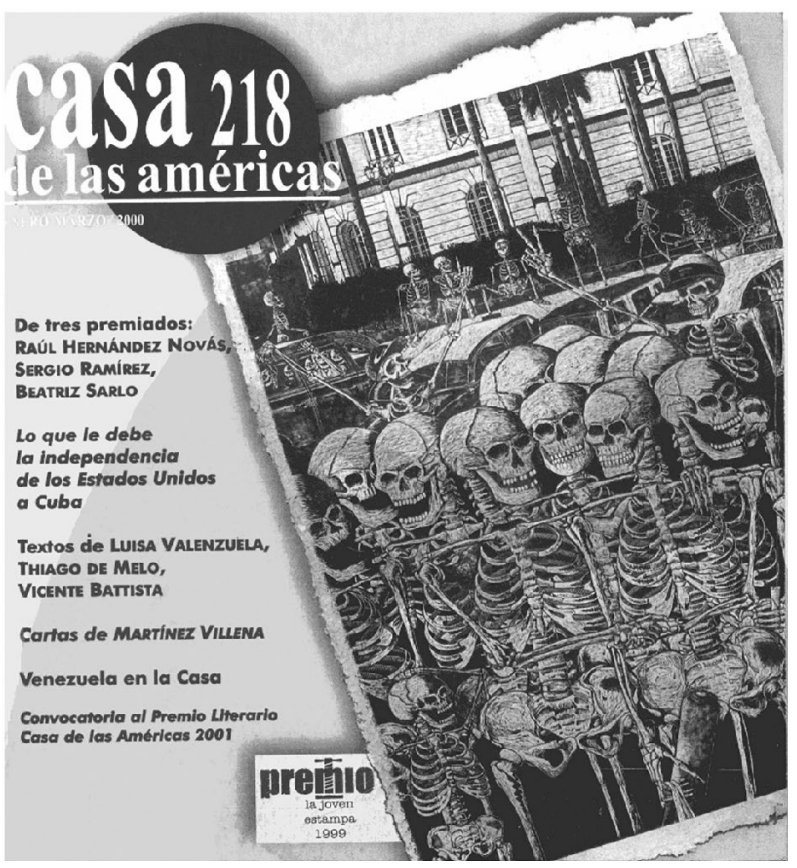
sumando un total de treinta y siete trabajos. De lo anterior puede deducirse que, aun cuando se trata de una publicación de ancho perfil cultural, es significativa la sistematicidad con que han sido atendidas las artes visuales. Anualmente la revista ha albergado en sus páginas al menos uno, y hasta cuatro trabajos, los que incluyen reseñas, textos ensayísticos, estudios monográficos y entrevistas. Los mis- 
mos se asocian, fundamentalmente, a dos de sus secciones fijas, a saber: "Artes Plásticas" y "El Libro". A través de esta última, los lectores de Casa de las Américas han tenido conocimiento de importantes acontecimientos editoriales relacionados con el tema objeto de estudio, en virtud de importantes reseñas de libros como: Frida Khalo en su luz más íntima, Escrituras de Frida Khalo; Diego Rivera, luces y sombras; Historia del Diseño en América Latina y el Caribe, etc.

En particular la sección "Artes Plásticas", como su denominación lo indica, ha sido el espacio privilegiado para dar cuenta de múltiples exposiciones personales y colectivas de artistas latinoamericanos y caribeños celebradas en Casa de las Américas, y para reseñar el desarrollo de diversos eventos tales como coloquios, premios y concursos convocados por la propia institución -tal es el caso del Premio La Joven Estampa- y otros de particular relevancia nacional e internacional como la Bienal de La Habana. Entre las veintidós reseñas localizadas figuran las dedicadas a importantes exposiciones colectivas realizadas en el período, tales como: la que un amplio número de grabadores mexicanos realizara en 1992; la muestra itinerante "Iberoamérica Pinta"; la exposición "Las Antillas/ West Indies"; la exposición "De la abstracción... al arte cinético"; la muestra de siete artistas centroamericanos titulada "Del Centro a la Isla", etc. Entre las reseñas de exposiciones personales destacan: la del fotógrafo guatemalteco Luis González Palma; la de los pintores mexicanos Francisco Toledo y Manuel Felguérez; la de la creadora chilena Gracia Barrios; y la muestra del reconocido creador argentino Antonio Berni, realizadas todas en diferentes sedes expositivas de la Casa de las Américas. Las páginas de la publicación han acogido, asimismo, sendas reseñas de ese importante evento de grabado que es el Premio La Joven Estampa, en lo que atañe al desarrollo de su tercera, cuarta y novena ediciones. Es menester acotar que también resultan útiles los artículos de corte noticioso acogidos en la sección "Recientes y Próximas de la Casa", los cuales dan fe del acontecer cultural de la institución ${ }^{4}$, incluida la presencia de las artes visuales, ya sea de manera protagónica o en su relación con otros certámenes y actividades.

Por su parte, los diez estudios monográficos registrados en esta pesquisa han privilegiado el acercamiento a la poética de grandes artistas del

4 Estos trabajos breves, situados en la publicación en formato de columnas noticiosas, no han sido incluidos en este estudio pero merecen justa mención al aludir al lugar que las artes visuales han ocupado dentro del contexto de la revista Casa de las Américas. 
área entre los que figuran: el puertorriqueño Lorenzo Homar, los chilenos Roberto Matta y José Balmes, y los mexicanos Frida Khalo, Lucía Maya y José Luis Cuevas. También se cuenta con una importante entrevista realizada a la fotógrafa mexicana Graciela Iturbide.

En cuanto a los cuatro textos ensayísticos localizados, han abordado áreas temáticas de inestimable interés para los estudiosos del arte; como es el caso del estudio panorámico sobre el desarrollo de la fotografía latinoamericana; el análisis de la relación entre el arte y las prácticas religiosas en el Caribe; el proyecto haitiano "Esculturas urbanas"; y, el arte público como opción de socialización de las prácticas artísticas contemporáneas, este último asunto desde la óptica de un creador de amplia experiencia en esta esfera como lo es el venezolano Carlos Cruz Diez.

Respecto a los colaboradores de la revista Casa de las Américas debe señalarse la concurrencia de una veintena de firmas que han prestigiado las páginas de la publicación con textos que reflejan un alto nivel profesional y que han contribuido con creces a la difusión de la producción plástica de América Latina y el Caribe. La nómina incluye académicos, investigadores, críticos, curadores y artistas. Si bien en el orden cuantitativo prima la presencia de autores cubanos de la talla de Adelaida de Juan, Yolanda Wood, Gerardo Mosquera, Nelson Herrera Ysla, Manuel López Oliva, David Mateo y Lourdes Benigni, en el caso de esta revista llama la atención la asidua colaboración de personalidades de otras naciones del área entre las que figuran: el artista uruguayo Carlos Capelán; la creadora e historiadora del arte haitiana Bárbara Prézeau; el artista venezolano Carlos Cruz Diez; el pintor y diseñador chileno Hugo Rivera; el ensayista puertorriqueño Arcadio Díaz; el escritor francés Alain Jouffroy; y el prestigioso investigador y teórico chileno Miguel Rojas Mix.

Revista Anales del CARIBE

Coterránea de la publicación Casa de las Américas, Anales del Caribe a lo largo del margen temporal que cubre este estudio, comporta un total de doce números, de los cuales una inmensa mayoría -diez- le han dado cabida en sus páginas a la temática en análisis. Ello implica que dicha publicación, sin ser una revista especializada en artes visuales, le ha concedido una importancia capital a la producción artística de la región caribeña, concediéndole veintiún textos. La mayoría se han desplegado 
como artículos de fondo; once de ellos son textos ensayísticos sobre temas generales, siete se ocupan de estudios monográficos, mientras que otros tres constituyen reseñas.

La dominante presencia de los trabajos ensayísticos -desplegados como textos autónomos de entre seis y doce páginas- refleja el carácter y estructura de una publicación en la que priman los artículos de alta densidad teórica. Un factor de suma importancia es la pluralidad de los temas

Revista Anales del Caribe

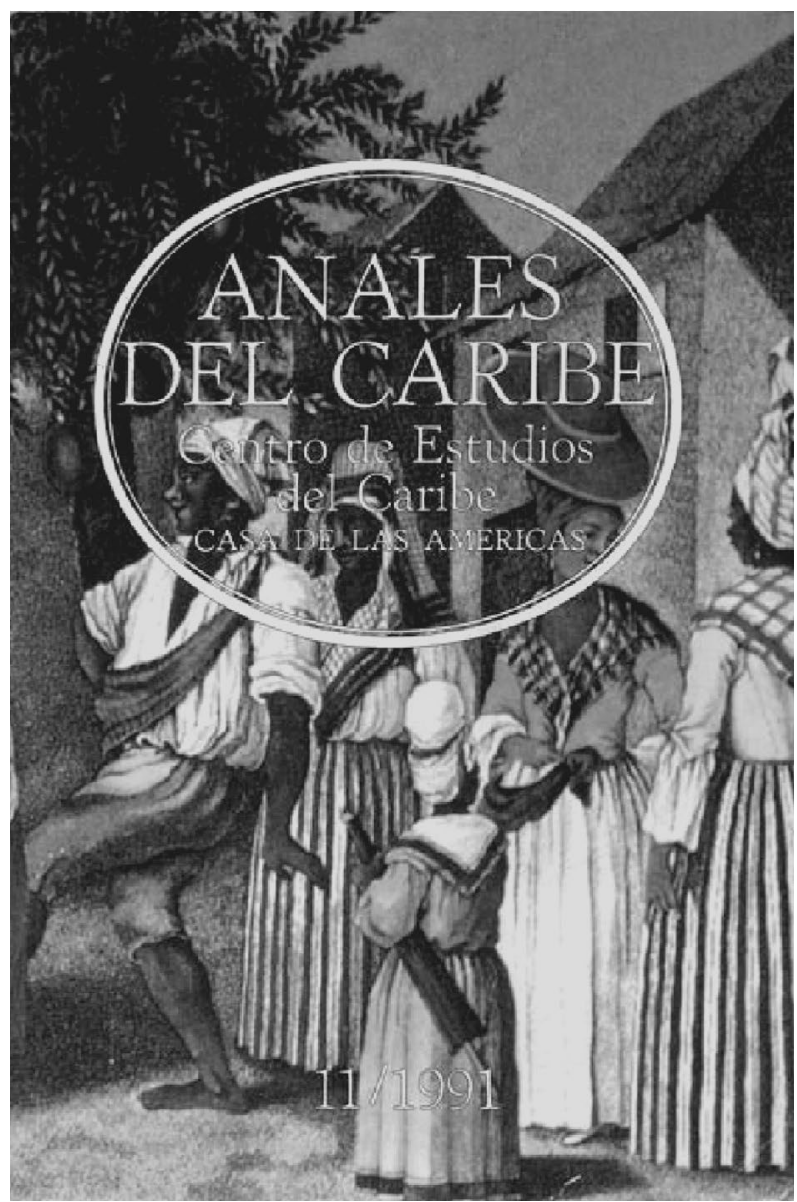

abordados, dedicando espacio a miradas que profundizan en determinadas zonas de las prácticas artísticas de alguna nación en particular-como la pintura puertorriqueña del siglo $\mathrm{xx}, \mathrm{y}$ el arte popular haitiano- o a interrelaciones verdaderamente reveladoras para el estudio del arte de la 
región como lo son, por ejemplo: su interconexión con África; el fenómeno de la intertextualidad y su implementación por parte de muchos de nuestros creadores; la impronta de la problemática de la violencia en nuestras artes visuales; la aportación de las mujeres artistas; y la participación caribeña en diferentes ediciones de la Bienal de La Habana.

En el contexto de los análisis monográficos un lugar prominente lo ha ocupado la figura del creador boricua Antonio Martorell cuyo magisterio resulta justamente reconocido por más de un texto en las páginas de Anales del Caribe. Artistas de otras naciones como República Dominicana, Martinica, Aruba y Trinidad y Tobago han sido objeto de análisis a partir de las poéticas de Tony Capellán, Henry Guédon, Ryan Oduber y Abigail Hadeed. En cuanto a las reseñas, contempladas en las secciones "Marginalia" y "Crónicas", se localizan tres trabajos de indudable valía, sobresaliendo muy especialmente el dedicado a la IV Bienal de Arte del Caribe, celebrada en Santo Domingo. Mientras que en la sección "Libros y Revistas" se ubica la elogiosa reseña del libro-catálogo del artista haitiano Jean Claude Garoute (Tiga).

Más allá de la valiosa colaboración de la creadora y estudiosa haitiana Bárbara Prézeau, el resto de las firmas que rubrican los textos son de autores nacionales. Debe destacarse, sin embargo, la afortunada concurrencia de ese grupo de historiadores del arte cubano que han tenido una participación verdaderamente protagónica en los estudios que sobre las artes visuales caribeñas se han potenciado desde nuestro país, a lo largo de los últimos veinte años. Encabezados por las catedráticas Adelaida de Juan y Yolanda Wood, profesoras ambas de la Universidad de La Habana y desde allí fundadoras de los estudios sobre el arte del Caribe en Cuba, se dan cita en Anales... las voces de: José Manuel Noceda, curador principal para el área del Caribe (y Centroamérica) del Centro de Arte Contemporáneo Wifredo Lam y de la Bienal de La Habana; Ivonne Muñiz, quien durante varios años se desempeñó como investigadora del Centro de Estudios del Caribe de la Casa de las Américas; Nahela Hechavarría, especialista de la Dirección de Artes Plásticas de la propia institución; el destacado investigador, curador y crítico Gerardo Mosquera; y, Enerdo Martínez, quien durante mucho tiempo ejerció también como profesor de Arte del Caribe en la Facultad de Artes y Letras de la Universidad de La Habana. Todos ellos, junto a jóvenes historiadores del arte que se sintieron estimulados por la directiva de la revista a situar en sus páginas valiosos acercamientos a las prácticas artísticas regionales, han hecho de esta publicación un ám- 
bito de referencia imprescindible para aquilatar cuánto se ha contribuido, desde Cuba, a la difusión del arte caribeño.

\section{BALANCE GENERAL DE LA INFORMACIÓN ACOPIADA EN LAS REVISTAS ARTE- CUBANo, ARTE POR EXCELENCIAS, ARTE SUR, CASA DE LAS AMÉRICAS Y ANALES DEL CARIBE}

Ciertamente al cierre del análisis de las revistas comprendidas en este trabajo procede realizar una evaluación general de los resultados que ha arrojado el rastreo de las artes visuales de Latinoamérica y el Caribe en dichas publicaciones. En este punto resulta imprescindible aventurarse en un análisis cuantitativo y cualitativo sobre la información acopiada, lo que permitirá corroborar cómo la crítica de artes visuales latinoamericanas y caribeñas en las revistas especializadas cubanas, en el período 1990 - 2011, se enriquece con respecto a etapas precedentes y refleja una diversidad de miradas que hacen énfasis, no solo en figuras e hitos del proceso histórico artístico de la región, sino en el quehacer más contemporáneo, lo que favorece su (re)conocimiento por parte de creadores y estudiosos cubanos.

De manera general, en las revistas Artecubano, Arte por Excelencias, Arte Sur, Casa de las Américas y Anales del Caribe se ha localizado una suma considerable de textos referidos a las artes visuales de América Latina y el Caribe, los cuales acumulan en su totalidad 183 artículos que incluyen textos ensayísticos, estudios monográficos, entrevistas y reseñas, cada una de estas modalidades con diverso protagonismo en las diferentes publicaciones. En el orden cuantitativo priman las reseñas -setenta y seis trabajos de este tipo- las que aluden a un amplísimo espectro de exposiciones y certámenes del mayor interés para las artes visuales de nuestra área geográfica, con lo que se ofrece el inapreciable testimonio de la creciente promoción que el arte latinoamericano y caribeño ha cobrado en los últimos veinte años.

Entre los eventos más frecuentados por los autores de reseñas se ubica, en primerísimo lugar, la Bienal de La Habana, lo que constituye un saldo lógico no solo por el hecho de que se ha trabajado con publicaciones cubanas, sino por la excepcional importancia que la misma ha cobrado para la producción artística de nuestra región. Asimismo otros acontecimientos de naturaleza equivalente como la Bienal de Cuenca, la Bienal de Video y Artes Mediales en Chile, la Trienal de Chile, la Trienal Poligráfica de San Juan, la Bienal de Tipografía en Buenos Aires, la Bienal de Arte de Panamá, la Bienal de Curitiba (Brasil), la Bienal del Mercosur, 
la Bienal de Sao Paulo, la Bienal de Arte Paiz (Guatemala), la Bienal Arte Nuevo Interactiva (México), la Bienal de Artes Visuales del Istmo Centroamericano, y la Bienal de Arte del Caribe han sido objeto de atención por parte de las publicaciones periódicas cubanas. También, en términos de certámenes las revistas han reflejado los saldos del Premio Ensayo Fotográfico y del Premio La Joven Estampa auspiciados, desde La Habana, por la Casa de las Américas; así como un considerable número de exposiciones personales y colectivas de artistas del área celebradas tanto en la isla de Cuba como en otras ciudades de Latinoamérica y el Caribe. Con ello, esta labor difusora ha implicado al quehacer promocional que en las dos últimas décadas ha tenido lugar en un amplio conjunto de naciones; entre las más representadas se encuentran México, Argentina, Brasil, Guatemala, Puerto Rico, Chile, Panamá, Haití y, por supuesto, Cuba.

Sesenta y dos textos ensayísticos contribuyen a ensanchar este mosaico de países cuyas prácticas artísticas contemporáneas han sido inquiridas y divulgadas a través de las publicaciones cubanas. Entre las miradas crítico-valorativas concentradas en contextos nacionales se localizan sendos trabajos referidos al arte abstracto en Argentina, al diseño y a la videocreación en Brasil, al panorama actual de las artes visuales en Nicaragua, a la temática del paisaje en Ecuador, al escenario escultórico en la República Dominicana, a la pintura del siglo xx en Puerto Rico y al arte popular en Haití.

Específicamente en lo concerniente al Caribe, amen de lo ya mencionado, adquieren un valor indudable los análisis que proponen una mirada integradora del área. Tal es el caso, por ejemplo, de los estudios referidos a las relaciones entre el arte y la religiosidad popular y a la huella africana en las artes visuales caribeñas; así como el de los acercamientos que han explorado zonas temáticas o vehículos de expresión -la violencia, el uso del cuerpo, la intertextualidad- que permiten dilucidar importantes puntos de contacto entre creadores y poéticas de diferentes países, o el de aquellos ensayos que han conseguido ofrecer una visión sumamente actualizada de la creación plástica caribeña en sentido general.

Llama la atención no ya la inmediatez crítico-valorativa, sino la pluralidad de enfoques que distingue a una buena parte de los textos y el rigor teórico que en no pocos casos apela al entrecruzamiento de saberes propios de la historia del arte, la filosofía, la psicología, la antropología cultural y otras disciplinas. En tal sentido, el análisis de la problemática del mercado y su incidencia múltiple en el escenario artístico actual de América Latina y el Caribe, y los retos de su inserción en el circuito in- 
ternacional, han ocupado un espacio nada desdeñable que contribuye al reconocimiento de un imperativo cultural de inapelable vigencia.

Asimismo, los estudios monográficos -treinta y un textos- han sido sumamente aportadores, ya que han contribuido con nuevas miradas a destacar la actividad de artistas de América Latina y el Caribe altamente representativos de las más diversas manifestaciones tales como la pintura, el grabado, la fotografía, el performance, la instalación, etc. Entre los creadores abordados se localizan la colombiana Libia Posada, la boliviana Alejandra Alarcón, la anglo-argentina Sara Hooper, las argentinas Dolores Cáceres y Mónica Girón, el uruguayo Luis Camnitzer, los brasileños José Damasceno y Ding Musa, el chileno Edwin Rojas, la guatemalteca Regina Galindo, los venezolanos Bárbaro Rivas y Jesús Rafael Soto, los puertorriqueños Antonio Martorell y Lorenzo Homar, el dominicano Tony Capellán, el martiniqués Henry Guédon, los chilenos José Balmes y Roberto Matta, los mexicanos Lucía Maya, Teresa Margolles, Frida Khalo y José Luis Cuevas, y la trinitaria Abigail Hadeed, et.al.

Por último, una zona a considerar la ocupan las catorce entrevistas localizadas en los marcos de este estudio. Estos trabajos devienen eficaces vehículos para indagar en la trayectoria y el quehacer actual de sobresalientes figuras, con el particular atractivo de conferirle voz propia a los creadores. Entre los entrevistados se encuentran los puertorriqueños Antonio Martorell y Víctor Vázquez, el mexicano Guillermo Gómez Peña, los brasileños Cildo Meireles y Paulo Bruscky, el chileno Iván Navarro, las mexicanas Ambra Polidori y Graciela Iturbide, el peruano Rafael Hastings y el boliviano Roberto Mamani. Mientras, dentro del amplio campo del arte y la cultura han explicitado sus opiniones personalidades como el culturólogo y crítico paraguayo Ticio Escobar, y los curadores José Manuel Noceda (Cuba), Alberto Grottesi (Argentina), Jorge Sepúlveda (Chile) y Raúl Moarquech (de origen cubano, radicado en México).

Estas amplias relaciones nominales ponen de relieve el ancho espectro geográfico que cubren las voces críticas que han colaborado con las distintas publicaciones revisadas, destacando el hecho de que no solo se atienden figuras pertenecientes a países tradicionalmente privilegiados por la crítica especializada -como México, Brasil y Argentina- sino también a otros menos favorecidos como Chile, Uruguay, Bolivia, Perú, Paraguay, Puerto Rico, Martinica, República Dominicana, Guatemala y Trinidad y Tobago. 


\section{BALANCE GENERAL DE LOS COLABORADORES DE LAS REVISTAS ARTECUBANO,} ARTE POR EXCELENCIAS, ARTE SUR, CASA DE LAS AMÉRICAS Y ANALES DEL CARIBE.

La nómina de colaboradores de las cinco publicaciones en el margen temporal revisado (1990-2011) suma 101 firmas; se trata pues de un centenar de especialistas -académicos, investigadores, curadores, críticos, escritores, periodistas y creadores- que a lo largo de dos décadas han aportado, desde las revistas cubanas, una mirada definitivamente plural sobre las artes visuales de América Latina y el Caribe.

El 53\% de ese total (54 de 101), como resulta perfectamente presumible, son autores cubanos. ${ }^{5}$ En este segmento se concentra, asimismo, la inmensa mayoría de los colaboradores que han publicado una cifra superior a tres textos per cápita. ${ }^{6}$ Ellos son: la destacada profesora, investigadora y crítica Adelaida de Juan, con catorce textos publicados (en tres de las revistas estudiadas, fundamentalmente en Casa de las Américas); la también profesora universitaria, investigadora, crítica y actual Directora del Centro de Estudios del Caribe de la institución Casa de las Américas Yolanda Wood, con ocho textos publicados (distribuidos estos en todas y cada una de las publicaciones revisadas); los investigadores y curadores del Centro de Arte Contemporáneo Wifredo Lam, Ibis Hernández y José Manuel Noceda, ambos con siete trabajos cada uno (Noceda en cuatro de las revistas; Hernández en tres de ellas); los también especialistas del propio Centro de Arte Contemporáneo, Nelson Herrera Ysla y Margarita Sánchez, con seis y cinco trabajos respectivamente (localizados en cuatro de las revistas revisadas en el caso de Herrera Ysla, y en tres en el de Sánchez); la investigadora, curadora y crítica Ivonne Muñiz, con cinco trabajos publicados (en dos de las publicaciones objeto de estudio); y el destacado creador y crítico Manuel López Oliva, con cuatro colaboraciones (incluidas en dos de las revistas).

Otros cubanos que figuran en la nómina de autores con más de una publicación son: el artista y crítico Antonio Eligio Fernández (Tonel); la creadora y promotora Lesbia Vent Dumois, quien por mucho tiempo estuvo

\footnotetext{
5 Esta cifra de 54 autores cubanos incluye varios (poco más de diez) que no residen actualmente en la isla. En algunos casos sus colaboraciones en las publicaciones estudiadas se produjeron en fechas en las que aún radicaban en el país. De cualquier modo, para este balance se ha asumido la nación de origen de los autores.

6 La única autora no cubana con más de tres publicaciones es la chilena Carolina Lara, con un total de cuatro textos, incluidos todos en la revista Arte por Excelencias.
} 
al frente de la Dirección de Artes Plásticas de la Casa de las Américas; las también especialistas de esa propia entidad, Nahela Hechavarría, Cristina Figueroa y Lourdes Benigni; Llilian Llanes, quien dirigió seis ediciones de la Bienal de La Habana y estuvo al frente del Centro de Arte Contemporáneo Wifredo Lam desde su fundación (en 1984) hasta el año 1999; el actual Director de dicho Centro, Jorge Fernández; el prestigioso crítico y curador Gerardo Mosquera; y otros destacados periodistas y críticos como Pedro de la Hoz y David Mateo, este último fungiendo, además, como editor de la revista Arte por Excelencias desde su fundación hasta el año 2011.

Con este resumen queda refrendada la observación formulada a propósito de los balances parciales antes presentados, acerca de la protagónica labor desarrollada en favor de la difusión del arte latinoamericano y caribeño en las principales publicaciones periódicas nacionales por parte de las más importantes personalidades que, tanto desde la academia (Departamento de Historia del Arte de la Facultad de Artes y Letras de la Universidad de La Habana), como desde instituciones culturales líderes de las artes visuales en Cuba (Casa de las Américas y Centro de Arte Contemporáneo Wifredo Lam) se han ocupado, en paralelo, de estimular el conocimiento, la investigación y la promoción del arte de nuestra región.

Entre los colaboradores no cubanos destacan, en términos cuantitativos, las participaciones de Venezuela (ocho), ${ }^{7}$ Brasil y Chile (seis), México, Uruguay y Argentina ${ }^{8}$ (tres), Puerto Rico y Colombia (dos). Figuran con dos o más publicaciones la esteta chilena Carolina Lara (cuatro textos en Arte por Excelencias), la crítica argentina -radicada en Paraguay- Adriana Almada (tres textos en Arte por Excelencias), la curadora y crítica brasileña Marissa Flórido (dos textos en Arte Sur y uno en Artecubano), la investigadora venezolana Isabel Huizi (dos colaboraciones en Arte Sur), y la creadora, curadora e historiadora del arte haitiana Bárbara Prézeau (con sendas colaboraciones en Casa de las Américas y Anales del Caribe). Otras firmas de indiscutible relieve en el ámbito de la promoción, la crítica y el

Debe aclararse que esta cifra incluye a Norberto Codina, venezolano de nacimiento, aunque radicado en Cuba desde hace más de cincuenta años. Como antes se ha señalado, se ha preferido respetar el país de nacimiento de los colaboradores a los efectos de los balances estadísticos.

8 Por la misma razón explicada en la nota anterior, se contabiliza como argentina a la curadora y crítica Adriana Almada, nacida en Argentina pero radicada en Paraguay, desde donde ha desarrollado su labor intelectual, llegando a fungir como Presidenta del capítulo paraguayo de la Asociación Internacional de Críticos de Arte (AICA). 
pensamiento sobre el arte, aunque con un solo texto en alguna de las revistas analizadas, han hecho también una valiosa contribución a la difusión del arte de nuestra región a través de las publicaciones cubanas. Se trata de prestigiosos curadores, museólogos, críticos y/o estudiosos entre los que figuran: los brasileños Tadeu Chiarelli, Moacir Dos Anjos y Leonor Amarante; el colombiano Guillermo Vanegas; la martiniqués Dominique Brebión; la boliviana Cecilia Bayá, los chilenos Justo Pastor Mellado y Miguel Rojas Mix; el español Santiago Olmo y la estadounidense Julia Herzberg.

La presencia de firmas de autores europeos y estadounidenses, aunque es algo que se manifiesta de manera puntual (solo 10 colaboraciones de 9 firmas), ${ }^{9}$ tiene el mérito de ofrecer esa perspectiva necesariamente diferente según la cual el arte latinoamericano y caribeño es apreciado desde los llamados centros hegemónicos. Por lo demás, es un hecho significativo que la inmensa mayoría de los colaboradores no cubanos (38 de 47) proceden de nuestra propia región geográfica. Al respecto compete señalar que, si bien se valora de muy positivo el saldo de la abundante presencia de estas firmas -sobre todo en publicaciones altamente inclusivas como Arte por Excelencias y Arte Sur-se advierte que las mismas incluyen, además de México, a casi todos los países del sur del continente ${ }^{10}$-Argentina, Bolivia, Brasil, Chile, Colombia, Ecuador, Uruguay y Venezuela- pero no incorporan, en cambio, a ningún exponente de la región centroamericana. Mientras que, en cuanto al Caribe, más allá de Cuba, solo se localizaron firmas de tres países, a saber: Haití, Martinica y Puerto Rico. Este déficit no se corresponde con el manifiesto interés con que dichas áreas han sido abordadas en las revistas analizadas, por lo que el dato pudiera constituir una alerta acerca de la pertinencia de ampliar, cuanto sea posible, el diapasón de voces críticas que en los años venideros pueden y deben ser acogidas en nuestras principales publicaciones.

\section{PARA TERMINAR...}

Indudablemente las publicaciones estudiadas han desempeñado un papel esencial en favor del conocimiento y la merecida valoración del acontecer artístico de América Latina y el Caribe entre los estudiosos cubanos du-

\footnotetext{
9 Se cuentan cuatro firmas procedentes de España, tres de Francia, una de Alemania y una de los Estados Unidos.

10 Solo faltan firmas de Guyana, Surinam, Paraguay y Perú; aunque habría que acotar que en el caso de Paraguay Adriana Almada aporta con creces la representación de ese país.
} 
rante las últimas dos décadas (1990-2011). En el lustro comprendido entre 1990 y 1995, Casa de las Américas y Anales del Caribe cumplieron este cometido con una sistematicidad loable, sobre todo teniendo en cuenta que se trata de publicaciones culturales de ancho espectro temático, cuya acción difusora atiende a las diversas manifestaciones de la cultura artística y al pensamiento social y cultural de nuestra región. Si se toma en consideración, además, que ese período abarca precisamente los años más difíciles del denominado "período especial", se aquilata mejor el mérito de haberse mantenido activas dentro del ámbito editorial, tan deprimido en aquella etapa, y de haber dado cabida a un total de trece textos sobre las artes visuales del área, la mayor parte de ellos dando fe de la sostenida labor llevada a cabo por la propia Casa de las Américas, aún en medio de las más adversas circunstancias materiales y financieras.

Un aprecio equivalente supone el surgimiento, en 1995, de Artecubano, en la medida en que esta publicación concretó el viejo anhelo de los investigadores, académicos, artistas, críticos y estudiosos cubanos del arte en general, de contar con una publicación especializada en artes visuales. Tal y como se anunciara en su primer número, la aspiración de esta revista no era solamente ofrecer "una respuesta a las expectativas que genera la creación contemporánea en Cuba", sino también "articular la noticia y la historia, los cauces conocidos y los enigmas por despejar; todo artista, tendencia u obra que de una manera $u$ otra, en el pasado o en el presente, haya contribuido al discurso de una identidad visual múltiple, diversa, abarcadora". (Carta del Director, 1995: 9)

En el concierto de esa identidad visual múltiple, diversa y abarcadora, la perspectiva, el sentido de pertenencia, el diálogo del arte cubano con la región latinoamericana y caribeña no podía dejar de ocupar un lugar sobresaliente. Así, en el quinquenio comprendido entre 1995 y 1999, se duplica el número de textos sobre la temática en estudio en las publicaciones nacionales -alcanzándose la cifra de otros veintiséis trabajos- debido, en gran medida, al invaluable concurso de Artecubano.

Los niveles de difusión de las artes visuales de América Latina y el Caribe mantuvieron un sostenido incremento a lo largo de los años 2000', hasta que definitivamente alcanzaron cotas impensables para etapas precedentes, a partir del surgimiento de Arte por Excelencias y Arte Sur. Las estadísticas lo ilustran por sí mismas: Artecubano, Casa de las Américas y Anales del Caribe acogieron en sus páginas, entre 1990 y 2011, la nada desdeñable cifra de noventa y tres textos sobre la materia. En tan solo dos 
años -desde sus respectivas apariciones en 2009 y hasta el 2011-Arte por Excelencias y Arte Sur han publicado otros noventa trabajos. Tamaño salto cualitativo solo puede explicarse desde de los presupuestos editoriales de las dos nuevas revistas. Arte por Excelencias, iniciativa del denominado Grupo Excelencias que a su vez es parte de un acuerdo de colaboración con la UNESCO, se presentó ante el público cubano y extranjero como una publicación que pretende "dejar testimonio de los procesos creativos dentro de las artes plásticas y sus protagonistas en países de las Américas y el Caribe (...) desde la perspectiva del periodismo cultural y su multiplicidad de géneros, para conformar un espacio de alcance internacional, dirigido a la consolidación del pensamiento analítico y reflexivo". (de Santiago, 2009: 3)

Mientras que Arte Sur, publicación financiada por el Proyecto Grannacional ALBA Cultural y concretada desde Cuba bajo la coordinación del Consejo Nacional de las Artes Plásticas, se plantea como propósito primordial erigirse en una "nueva publicación de arte descolonizadora, plural, profunda, abierta y solidaria, que contribuya a diseñar una justa cartografía de nuestra presencia en el ámbito contemporáneo, y suponga una alternativa a los dictámenes totalizadores y excluyentes del mercado transnacional". (Editorial, 2009: p. 3).

De los 183 textos localizados en esta pesquisa, catorce constituyen entrevistas a artistas y personalidades del circuito del arte; treinta y un trabajos califican como estudios monográficos centrados en la obra y/o trayectoria de creadores en específico; sesenta y dos textos son trabajos de corte ensayístico sobre la producción artística regional o sobre temas directamente relacionados con la promoción, la comercialización, el pensamiento teórico sobre el arte, etc.; y setenta y seis trabajos se dedican a reseñar un amplísimo espectro de libros, exposiciones individuales y colectivas; así como certámenes nacionales, regionales e internacionales de máximo interés para los países del área por la sustanciosa presencia que en sus predios alcanza el arte de nuestra región.

Ha podido advertirse una saludable pluralidad de enfoques y una densidad teórica estimable, especialmente en aquellos textos que, sin desconocer las especificidades de creadores, poéticas, contextos nacionales y otras diversidades concurrentes, se proponen articular miradas integradoras que ponen en valor, en última instancia, la identidad cultural de América Latina y el Caribe y su expresión en nuestras artes visuales. Asimismo, se ha podido comprobar que los directivos y editores de las publicaciones cubanas estudiadas han procurado abrazar en sus páginas 
las problemáticas y las contribuciones de la mayor cantidad de territorios posible dentro de nuestra ancha geografía regional, atendiendo con particular interés los ámbitos caribeños y centroamericanos, cuya pujanza y visibilidad internacional constituyen fenómenos muy estimulantes en el marco temporal analizado.

En cuanto a los voces críticas identificadas, casi la mitad de los colaboradores con los que se ha contado para el abordaje del tema objeto de estudio son autores extranjeros: 47 de un total de 101; entre estos predominan los latinoamericanos y caribeños (38), aunque se lamenta la falta de representación de especialistas de Centroamérica y de casi todo el territorio Caribe (excepto Martinica, Puerto Rico y Haití). Esto último denota una carencia perfectamente superable a corto plazo, dado el amplio diapasón de relaciones que han abierto estas publicaciones con los investigadores, académicos, críticos, promotores y artistas de esta región del mundo.

Los colaboradores cubanos, por su parte, constituyen el 53\% de las firmas (54 de 101). El registro realizado testimonia la sostenida y creciente voluntad de producción científica que ha tenido lugar desde Cuba en el campo de la historia del arte, la investigación y la crítica especializada. Esta producción científica ha sido alentada durante las dos últimas décadas, fundamentalmente desde el ámbito académico, en específico, a través de los estudios de licenciatura en Historia del Arte que se llevan a cabo en la Universidad de La Habana. Ello explica que una parte significativa entre los autores cubanos (justo el 50\% de estos) la ocupen egresados de esta carrera, quienes se han desempeñado como docentes, investigadores, curadores y críticos de arte en diferentes instituciones culturales cubanas y en la propia Universidad de La Habana.

Tras este análisis puede corroborarse que sin dudas desde el espacio intelectual cubano se está gestando un pensamiento cultural integrador, que apuesta por la difusión del arte de la región a partir de voces nacionales; así como le da cabida a autores del ámbito caribeño y latinoamericano para, en estrecho diálogo, potenciar, diversificar y enriquecer las miradas con las que hasta hoy se han comprendido las prácticas artísticas que tienen lugar en el complejo, multicultural y plurilingüístico espacio de América Latina y el Caribe. 
BIBLIOGRAFÍA

FUENTES DE PRIMERA MANO:

Revista Anales del Caribe / Todos los números de la publicación comprendidos en el período 1990-2011, lo que incluye del No. 10, 1990, hasta el Número correspondiente al año 2008.

Subtotal: doce números

No. 10, 1990; No.11, 1991; No.12, 1992; No.13, 1993; No.14/15, 1995; No.16-18, 1996-1998; No.19-20, 1999-2000; 2003; 2004; 2005/2006; 2007; 2008.

Revista Arte por Excelencias / Todos los números de la publicación comprendidos en el período 1990-2011, lo que incluye del No. 1, Año I, 2009 hasta el No. 11/12, Año III, 2011.

Subtotal: once números

No.1, Año I, 2009; No.2, Año I, 2009; No.3, Año I, 2009; No.4, Año I, 2009; No.5, Año I, 2009; No.6, Año I, 2009; No.7, Año I, 2009; No.8, Año I, 2009; No.9, Año I, 2009; No.10, Año III, 2011; No. 11/12, Año III, 2011.

Revista Arte Sur / Todos los números de la publicación comprendidos en el período 1990-2011, lo que incluye del Volumen 1, 2009 hasta el Volumen 2, 2010.

Subtotal: dos números

Volumen 1, 2009; Volumen 2, 2010.

Revista Artecubano / Todos los números de la publicación comprendidos en el período 1990-2011, lo que incluye del No. 1, 1995 hasta el No. 3, 2010.

Subtotal: treinta y seis números

No. 1 y No. 2 de 1995; No. 1 y No. 2 de 1996; No. 1 de 1997; No.1 y No.2 de 1998; No. 1 y No. 2 de 1999; No. 1, No. 2 y No. 3 de 2000; No. 1, No. 2 y No. 3 de 2001; No. 1, No. 2 y No. 3 de 2002; No. 1 y No. $2 / 3$ de 2003; No. 1 y No. 2 de 2004; No. 1 y No. 2 de 2005; No. 1 y No. 2 de 2006; No. 1 de 2007; No. 1 , No. 2, y No. 3 de 2008; No. 1, No. 2 y No. 3/4 2009; No. 1, No. 2 y No. 3 de 2010.

Revista Casa de las Américas / Todos los números de la publicación comprendidos en el período 1990-2011, lo que incluye del No. 178, Año XXX, 1990, hasta el No. 265, Año L, 2011. 
Subtotal: ochenta y ocho números: No. 178, 1990; No. 179, 1990; No. 180, 1990; No. 181, 1990; No. 182, 1991; No. 183, 1991; No. 184, 1991; No. 185, 1991; No.186, 1992; No.187, 1992; No.188, 1992; No.189, 1992; No.190, 1993; No.191, 1993; No.192, 1993; No.193, 1993; No.194, 1994, No.195, 1994; No.196, 1994; No.197, 1994; No.198, 1995; No.199, 1995; No.200, 1995; No.201, 1995; No.202, 1996; No.203, 1996; No.204, 1996; No.205, 1996; No.206, 1997; No.207, 1997; No.208, 1997; No.209, 1997; No.210, 1998; No.211, 1998; No.212, 1998; No.213, 1998; No.214, 1999; No.215, 1999; No.216, 1999; No.217, 1999; No.218, 2000; No.219, 2000; No.220, 2000; No.221, 2000; No.222, 2001; No.223, 2001; No.224, 2001; No.225, 2001; No.226, 2002; No.227, 2002; No.228, 2002; No.229, 2002; No.230, 2003; No.231, 2003; No.232, 2003; No.233, 2003; No.234, 2004; No.235, 2004; No.236, 2004; No.237, 2004; No.238, 2005; No.239, 2005; No.240, 2005; No.241, 2005; No.242, 2006; No.243, 2006; No.244, 2006; No.245, 2006; No.246, 2007; No.247, 2007; No.248, 2007; No.249, 2007; No.250, 2008; No.251, 2008; No.252, 2008; No.253, 2008; No.254, 2009; No.255, 2009; No.256, 2009; No.257, 2009; No.258, 2010; No.259, 2010; No.260, 2010; No.261, 2010; No.262, 2011; No.263, 2011; No.264, 2011; No.265, 2011.

\section{FUENTES BIBLIOGRÁFICAS:}

ADES, D. (1989); Art in Latin America. The Modern Era, 1820-1980 . Estados Unidos: Yale University Press.

"Carta del Director". (1995); en Artecubano, No.1, pp. 9.

DE SANTIAGO, J. (2009); en Arte por Excelencias, No. 1 (Año I), pp. 3.

EDITORIAL. (2009); en Arte Sur, Volumen 1, pp. 3.

FERNÁNDEZ, R. (2010); "Sobre la revista Casa de las Américas”, en Casa de las Américas, No. 258, (Año XLIX, enero-marzo), pp. 3-9.

GUTIÉRREZ, R. (2005); Arte Latinoamericano del siglo XX. Otras historias de la Historia. Zaragoza: Prensas Universitarias de Zaragoza.

HUIZI, I. (2009); “Arte Latinoamericano y mercado: de la pluralidad al mercado único", en Arte Sur, Volumen 1, pp. 24-27.

LÓPEZ, M. (2010); "Señales en el horizonte. Otra lectura del arte nuestroamericano", en Arte Sur, Volumen 2, pp.21-27.

LUCIE-SMITH, E. (2000); Arte Latinoamericano del siglo XX. Barcelona: Ediciones Destino Thames and Hudson.

SERRANO, E. (1987); Arte Latinoamericano. (Etapa Republicana). Selección de Lecturas. La Habana: Editorial Pueblo y Educación.

(1993); Arte Latinoamericano y Caribeño. Selección de Lecturas. La Habana: Editorial Félix Varela. 
SUlLIVAN, E. (1996); Latin American Art in the Twentieth Century. London: Phaidon Press Limited.

WOOD, Y. (1990); De la plástica cubana y caribeña. La Habana: Editorial Letras Cubanas.

(1993); Las artes plásticas en el Caribe: pintura y grabado contemporáneos. La Habana: Editorial Pueblo y Educación.

(1998); Artistas del Caribe hispano en Nueva York. La Habana: Editorial Letras Cubanas.

, (2000); Artes plásticas en el Caribe: praxis y contextos. La Habana: Editorial Félix Varela.

, (2012); Islas del Caribe: naturaleza-arte-sociedad. La Habana: Editorial U.H y Consejo Latinoamericano de Ciencias Sociales.

FUENTES ORALES:

\section{ENTREVISTAS REALIZADAS A:}

Figueroa, Cristina. Especialista de la Dirección de Artes Plásticas de la Casa de las Américas. La Habana, octubre 17 de 2010.

Hechavarría, Nahela. Especialista de la Dirección de Artes Plásticas de la Casa de las Américas. La Habana, octubre 17 de 2010.

López, Manuel. Artista y crítico de arte; integrante del Consejo Editorial de la revista Arte Sur. La Habana, diciembre 7 de 2011.

Rodríguez, Kirenia. Profesora Instructora de Arte Latinoamericano del Departamento de Historia del Arte de la Universidad de La Habana, y colaboradora del Centro de Estudios del Caribe de la Casa de las Américas. La Habana, octubre 15 de 2010.

Veigas, José. Investigador, crítico y curador; colaborador permanente de la revista Arte por Excelencias, a cargo de la sección "El Archivero". La Habana, abril 24 de 2012.

Wood, Yolanda. Profesora Titular de Arte Caribeño del Departamento de Historia del Arte de la Universidad de La Habana y Directora del Centro de Estudios del Caribe de la Casa de las Américas. La Habana, octubre 15 de 2010. 